\title{
Sleep and plasticity
}

\author{
Sidarta Ribeiro
}

Received: 17 May 2011 /Revised: 6 September 2011 /Accepted: 14 September 2011 / Published online: 27 September 2011

(C) The Author(s) 2011. This article is published with open access at Springerlink.com

\begin{abstract}
While there is ample agreement that the cognitive role of sleep is explained by sleep-dependent synaptic changes, consensus is yet to be established as to the nature of these changes. Some researchers believe that sleep promotes global synaptic downscaling, leading to a nonHebbian reset of synaptic weights that is putatively necessary for the acquisition of new memories during ensuing waking. Other investigators propose that sleep also triggers experience-dependent, Hebbian synaptic upscaling able to consolidate recently acquired memories. Here, I review the molecular and physiological evidence supporting these views, with an emphasis on the calcium signaling pathway. I argue that the available data are consistent with sleep promoting experience-dependent synaptic embossing, understood as the simultaneous non-Hebbian downscaling and Hebbian upscaling of separate but complementary sets of synapses, heterogeneously activated at the time of memory encoding and therefore differentially affected by sleep.
\end{abstract}

Keywords Adenylyl cyclase $\cdot \mathrm{Ca}^{2+}$ dependence $\cdot \mathrm{cAMP}$. Electrophysiology · Gene expression · Hippocampus · Longterm potentiation $\cdot$ Long-term depression - Memory . Plasticity

\section{Introduction}

The involvement of sleep with learning and memory has been extensively demonstrated in various animal models

This article is published as part of the Special Issue on Sleep.

\section{S. Ribeiro $(\triangle)$}

Brain Institute,

Federal University of Rio Grande do Norte (UFRN),

Natal, Rio Grande do Norte, Brazil

e-mail: sidartaribeiro@neuro.ufrn.br including humans $[23,25,29,30,35,50,51,57,58,60$, $62,70,75-77,83,87,89,105,118,119,136-140,143$, 144, 147, 150, 151]. Furthermore, several electrophysiological and imaging studies provide comprehensive support and mechanistic basis for the notion that sleep promotes cognitive processing $[22,37,53,54,59,61,67,71,80,82$, $83,88,90,98,99,104,109,117,148]$. Recently, it was shown that memory quickly undergoes consolidation when reactivated during sleep while becoming labile after being reactivated during waking [25]. In relationship with these findings, most if not all sleep researchers agree that sleep promotes brain plasticity, understood as lasting changes in the strength of synaptic connections. But here the consensus ends, for at least two different views currently coexist in the literature.

One group of researchers postulate that sleep is fundamentally a state of synaptic downscaling, a homeostatic process by which synaptic weights saturated during waking would decrease to baseline levels, so as to enable further potentiation during subsequent waking [126, 127]. The proponents of this theory believe that sleep is associated with a net decrease of synaptic strength, while wakefulness produces the opposite effect, i.e., a net increase of synaptic strength. This view is mainly supported by evidence of (1) sleep-dependent downregulation of activitydependent gene transcripts, metabolic enzymes, calciumdependent protein kinases, and membrane trafficking proteins [135]; (2) electrophysiological potentiation during waking, with depotentiation during sleep [64, 135]; and (3) morphological enhancement of synapses during waking, with a reduction during sleep [7].

At partial odds with the notion presented above, an alternative view proposes that neuronal circuits may also undergo experience-dependent upscaling of synaptic weights during sleep, depending on the conditions of memory acquisition [23, 102]. This notion is originally 
grounded on experiments showing that post-learning sleep elicits an upregulation of the levels of calcium-dependent transcripts and proteins related to synaptic upscaling [100, $101,104,106,133]$. This body of data agrees well with the demonstration that sleep deprivation impairs calcium signaling required for synaptic upscaling in the hippocampus [134]. Further support for this view comes from the investigation of the role of sleep during development $[2,33$, 66, 112-115]. Very compelling evidence for synaptic upscaling during sleep has also been uncovered in fruit flies [26, 39].

The first aim of this article is to review the bodies of evidence regarding synaptic downscaling and upscaling during sleep. Despite the fact that the two conflicting theories are based on different assumptions and experimental strategies, the second aim of this article is to argue that the data available are actually compatible and complementary, in the sense that separate neuronal circuits undergo differential plasticity during sleep, leading to synaptic embossing [93, 103].

\section{Evidence of synaptic downscaling during sleep}

Donald Hebb was the first to clearly postulate that memory formation at the level of neuronal circuits requires the joint firing of pre- and post-synaptic neurons, which would lead to a local enhancement of synaptic efficacy and to a shortterm period of electrophysiological reverberation [49]. In addition, he proposed that long-term mnemonic consolidation should be critically dependent on the occurrence of morphological changes capable of producing lasting modifications on the strength of synaptic connections [49], a wellestablished fact nowadays [21, 44, 45, 141, 145]. The amnesic effect of protein synthesis blockers demonstrated decades ago that such morphological changes require de novo protein synthesis [42]. Since then, we learned that this process is governed by the activation of specific signaling cascades and gene expression programs [4, 74]. Long-term Hebbian plasticity is elicited by synchronous pre-synaptic firing that leads to sustained post-synaptic depolarization, capable of opening $N$-methyl $D$-aspartate (NMDA) channels [69], which allow for increased calcium entry and the consequent phosphorylation of calcium-dependent protein kinases $[5,34,63]$. The process eventually leads to the transcriptional upregulation of immediate early genes (IEG), which encode a variety of proteins related to changes in gene regulation and synaptic morphophysiology. Some IEG are direct effectors of neuronal plasticity, while other IEG code for indirect modulators of cell functioning, such as transcriptional regulators.

An important plasticity-related effector gene encodes for the activity-regulated cytoskeleton-associated (arc) protein, a calcium-dependent IEG that promotes synaptic remodeling by way of interactions with actin, glutamatergic $\alpha$-amino-3hydroxy-5-methyl-4-isoxazolepropionic acid (AMPA) receptors, and calcium/calmodulin-dependent protein kinase II (CaMKII). Arc mRNA is transported for local translation in dendrites, likely playing an important role in tagging specific synapses for plasticity $[47,68,120,142]$. The gene zif-268 (homologous to egr-1, NGFI-A, krox-24, and ZENK) is an example of a calcium-dependent gene with a regulatory plasticity function. Zif-268 encodes a transcription factor that putatively modulates the expression of hundreds of different genes [8, 78, 149], including synapsins I and II [92, 125], which are crucially involved in synaptic vesicle release [52].

The first attempt to assess the existence of sleep-dependent synaptic plasticity involved the use of protein synthesis blockers. This early experiment established a role for de novo protein synthesis in the cognitive effects of sleep because the blockade of protein synthesis during post-learning sleep markedly impairs memory consolidation [46]. With the discovery of calcium-dependent IEG in the late 1980s, many of which encode transcription factors required for memory consolidation, sleep researchers envisioned a causal Hebbian mechanism able to link short-term electrophysiological activation to long-lasting changes in synaptic morphophysiology. The reasoning at this point was quite straightforward: If sleep promotes memory consolidation and IEG are necessary for long-term plasticity, ergo the expression of IEG should be upregulated during sleep.

Contrary to this prediction, however, the pioneer assessments of the question found that rats investigated after long periods of sleep showed low levels of mRNA and protein encoded by the IEG c-fos and NGFI-A (zif-268), in comparison with the increased levels detected in sleepdeprived animals [94-97, 129]. Soon later, these results were confirmed by another group [85]. Eventually, the observations were extended to other IEG $[9,12,13,15-19$, 48, 128], calcium-dependent kinases, and other molecular markers of plasticity [135]. Additional support for synaptic downscaling during sleep comes from electrophysiological experiments in rats showing that the slope and amplitude of cortical evoked responses increase after waking but decrease after sleep [135]. Likewise, miniature excitatory post-synaptic currents recorded from rodent cortical slices are larger and more frequent after periods of waking than after periods of sleep [64]. A computational model that fits the data has been published [86].

Synaptic downscaling during sleep was proposed to be a general feature of vertebrates, as well as invertebrates, because studies in Drosophila melanogaster found that periods of sleep were associated with an increase in the levels of transcripts related to membrane trafficking proteins and a decrease in the expression levels of metabolic enzymes such as cytochromes, which are 
essential for respiration within mitochondria $[6,10,11,14$, $56,116]$. Furthermore, sleep was also associated with the transcriptional downregulation of the IEG arc, homer, and zif-268, as well as the brain-derived neurotrophic factor (BDNF) [13]. Very recently, a combination of Drosophila genetics with confocal microscopy and behavioral analysis directly showed that the size and number of synapses increase after waking and decrease after sleep [7]. Synaptic growth was even more prominent when a richer waking experience was provided. The study also investigated the role of the gene fragile X mental retardation 1 (Fmr1) in sleep-dependent synaptic renormalization. Fmr1 overexpression in the fruit fly brain abolished the wake-dependent increase in spine number, adding support to the notion that this gene plays a role in synaptic pruning [7].

Taken together, these results have been used to support the "synaptic homeostasis hypothesis" (SHY) proposed by Giulio Tononi and Chiara Cirelli [126, 127], by which sleep promotes a non-Hebbian downward adjustment of synaptic weights at the network level, in contrast to classic Hebbian forms of plasticity that act on specific circuits. SHY is intimately related to a more general principle called homeostatic synaptic plasticity, proposed by Gina Turrigiano to describe generalized synaptic scaling capable of maintaining the functional stability of neuronal circuits subjected to cumulative activity-dependent changes [130, 131]. According to this principle, a non-Hebbian negative feedback on the number and efficacy of synapses would counterbalance the positive feedback that characterizes Hebbian plasticity, leading to a renormalization of synaptic weights that would enable further Hebbian changes [132].

\section{Evidence of synaptic upscaling during sleep}

At variance with the findings described above, other research teams including mine have generated quite different results, based on distinct assumptions and therefore distinct experimental designs. To assess the mnemonic role of sleep, these experiments always took into account the need to compare animal groups with and without exposure to novel stimulation [41]. Furthermore, the experiments were designed to sort and compare the distinct contributions of slow-wave sleep (SWS) and rapid eye movement sleep (REM) because these states are characterized by quite different durations and neuronal activity regimes. Since SWS is much more abundant than REM [40], experiments that do not attempt to separate sleep states are dominated by SWS and therefore fail to address the effects of REM [13].

By adopting an experimental design with pre-sleep exposure to a novel environment and SWS/REM state sorting, I verified in rats that the first REM episode after exploration of a novel environment elicits an upregulation of zif-268 mRNA levels in the cerebral cortex and hippocampus, a phenomenon not observed in nonstimulated controls [100]. On the other hand, SWS consistently correlated with decreased zif-268 mRNA levels irrespective of prior exposure to novelty [100]. These results were corroborated by a subsequent study in which novel environment exploration was substituted by highfrequency stimulation of the hippocampus [101], a protocol used to induce long-term potentiation (LTP) [4]. The experiments revealed three spatiotemporally distinct waves of zif-268 expression, beginning proximally in the hippocampus 30 min after stimulation and reaching distal cortical and subcortical regions during the two ensuing REM episodes a few hours after LTP induction. Every wave of zif-268 mRNA upregulation initiated during REM, continued through waking, and was stopped by the subsequent SWS episode. Taken together, the data pointed to the existence of intermittent hippocampofugal plasticity as the sleep-wake cycle recurs, with synaptic downscaling favored by SWS and synaptic upscaling elicited by REM [101].

A few years later, the evidence of experience-dependent synaptic upscaling during REM was extended to other plasticity-related factors. An independent research group verified that, in rats trained in the active avoidance learning task, REM induces an experience-dependent upregulation of arc and BDNF protein levels, as well as an increased phosphorylation of the cyclic adenosine monophosphate response element-binding (CREB) protein [133]. In agreement with these data, my group went on to show that zif268 and arc mRNA levels continue to be upregulated by REM in the cerebral cortex (but not in the hippocampus) after dozens of post-novelty sleep cycles have elapsed [104]. One important finding of this study is that IEG upregulation elicited by post-novelty REM was strongly and positively correlated with the amplitude of local field potentials in the frequency range of spindles $(10-14 \mathrm{~Hz})$, neural oscillations associated with learning and LTP [20, $27,31,32,36,79,81,83,107,108,122-124,146]$. In contrast, IEG mRNA levels after post-novelty REM were not well correlated with firing rates. These results are in line with the notion that IEG expression is more related to dendritic inputs than to somatic outputs (action potentials) $[65,84]$. The data indicate that cortical spindles, which are particularly abundant in the transition between SWS and REM [40], may couple the robust mnemonic reverberation that characterizes the former $[22,37,53,54,59,61,67,71$, $80,82,83,88,90,98,99,104,109,117,148]$ to the IEG transcriptional upregulation triggered by the latter $[39,100$, $101,104,133]$. Such a mechanism could in principle explain the cognitive complementarity of the two main sleep states $[41,77,121]$. 
The investigation of sleep in invertebrates also yielded evidence of synaptic upscaling. Socially enriched fruit flies exposed to many males and females displayed significantly more sleep than socially impoverished isogenic siblings that were individually housed [39]. Sleep was modified by the most recent social experience so that socially impoverished flies with short sleep became longer sleepers when exposed to social enrichment; conversely, socially enriched flies with long sleep became short sleepers when exposed to social impoverishment. Repeated reversals of social enrichment to isolation and vice versa led to corresponding changes in sleep patterns, always reflecting the most recent experience. Whole-brain estimations of neurotransmitter levels showed that long-sleeping flies had three times more dopamine than short sleepers. The sleep decrease induced by social isolation was completely blocked when dopaminergic transmission was excessively up- or downregulated, indicating that normal levels of dopamine are required for this kind of behavioral plasticity [39]. To assess the underlying mechanisms of experience-dependent changes in sleep need, the researchers screened mutations in 49 genes associated with learning and memory. Post-impoverishment sleep decrease was blocked by 17 of these mutations, including those affecting the genes dunce and rutabaga, which have opposite effects on intracellular levels of cyclic adenosine monophosphate (cAMP) [39].

Very recently, Jeffrey Donlea, Paul Shaw, and collaborators published breakthrough evidence that sleep may either downscale or upscale synapses, depending on the experimental conditions [26]. Expression in specific Drosophila neurons of the temperature-gated nonspecific cation channel Transient receptor potential cation channel (UASTrpA1) allowed the experimenters to induce sleep simply by raising the ambient temperature from $25^{\circ} \mathrm{C}$ to $31^{\circ} \mathrm{C}$. The capacity to induce sleep on demand provided an opportunity to go beyond the correlative studies towards causal links because it made possible the investigation not only of the detrimental effects of the lack of sleep but also of the positive cognitive effects produced by increased sleep. In one set of experiments aimed at testing SHY, fruit flies were subjected to social enrichment or isolation for 5 days and then subjected to a long-term memory task. In addition, some groups were subjected to a transient increase in temperature $\left(25^{\circ} \mathrm{C}\right.$ to $\left.31^{\circ} \mathrm{C}\right)$ that elicited sleep. Flies subjected to isolation were capable of establishing longterm memory, but flies subjected to social enrichment and kept at $25^{\circ} \mathrm{C}$ were not. Since social enrichment caused an enhancement of synaptic terminals, it was hypothesized that the transient induction of sleep following social enrichment should rescue the capacity for long-term memory formation. Indeed, flies briefly exposed to $31^{\circ} \mathrm{C}$ after social enrichment recovered the capacity for long-term memory formation [26]. Another set of experiments, however, addressed the possibility that the cognitive role of sleep goes beyond reversing deficits in learning capacity caused by prolonged wakefulness. In this case, sleep was thermically induced immediately after a training protocol that induces short-term but not long-term memory. Remarkably, flies subjected to post-training sleep acquired long-term memory, indicating that sleep is not simply restorative of learning potential but can also constitute a positive driving force shaping learning [26].

Data in line with these findings have come from a very different topic of investigation, namely development. Studies of rats subjected to early-life REM deprivation showed a role for this state in the maturation of thalamic, cortical, and hippocampal circuits, with a decrease in the stability of long-term potentiation [66, 112-115]. An important developmental effect of sleep has been particularly well demonstrated with regard to ocular dominance columns in the visual cortex [2, 33]. By reversibly inactivating the visual cortex of sleeping cats after a period of monocular deprivation, Frank and collaborators sought to investigate the role of cortical activity in sleep-dependent plasticity. Optical imaging of intrinsic cortical signals and electrophysiological recordings showed that ocular dominance plasticity was significantly decreased when the visual cortices were inactivated during sleep [2, 33]. In a follow-up study, the researchers probed the role of NMDA receptors and calcium-dependent kinases. They found that plasticity was blocked by the intracortical infusion, during postmonocular deprivation sleep, of an antagonist of the NMDA receptor or of an inhibitor of the cAMP-dependent protein kinase (PKA) [2, 33]. They also verified that cats subjected to monocular deprivation and then allowed to sleep showed increased phosphorylation of the extracellular-signalregulated kinase (ERK), CaMKII, and the GluR1 subunit of the AMPA receptor. These increases in the phosphorylation of LTP-related kinases and an AMPA receptor subunit, all downstream of NMDA receptor/PKA activation, were not observed in cats unexposed to monocular deprivation or not allowed to sleep [2, 33].

A developmental role for sleep has also been discovered in invertebrates. Flies exposed to acute sleep deprivation on their first day of life showed long-lasting deficits in short-term memory [111]. These deficits were reversed by dopamine agonists, and the blockade of the dDA1 receptor in sleep-deprived animals during their critical developmental window prevented subsequent adult learning impairments [111].

A deeper understanding of the molecular consequences of post-learning sleep came from a study conducted by Romcy-Pereira and collaborators [106]. The researchers were interested in the activation of secondary genes related to local changes in synaptic strength and memory stabilization during sleep, after the initial wave of IEG induction. 
To this end, they assessed the hippocampal and cortical expression of plasticity-related genes at a late time with respect to the induction of zif-268 expression. Rats underwent uni-hemispheric LTP in the hippocampus and were then separated in waking versus REM groups, according to the behaviors allowed to occur in the postLTP period. Eighty minutes after displaying a long REM episode (or an equivalent amount of waking time in the control group), the animals were killed, the hippocampi and prefrontal cortices were dissected, and the samples were processed for gene microarray hybridization. The microarray analysis identified a total of 28 upregulated genes, with 13 genes upregulated by REM regardless of prior potentiation, 4 genes with increased levels in the potentiated hemisphere irrespective of behavioral state, and 11 genes selectively upregulated in the potentiated hemisphere of REM animals [106]. Confirmation essays with quantitative realtime PCR analysis in the LTP hippocampus of sleep animals demonstrated an upregulation of the transcription factor albumin D-site-binding protein, which modulates neuronal excitability and ERK expression in the hippocampus [110]. A trend for upregulation of the protein kinase CaMKI, which is involved with activity-dependent dendritic remodeling, was also observed. In the prefrontal cortex, the researchers found a significant LTP/sleep-dependent decrease of GluR1 and spinophilin transcripts, which encode for a subunit of AMPA receptors and a protein phosphatase-1 interacting protein, both highly enriched in dendritic spines and required for synaptic remodeling $[1,72]$. Overall, the results indicate that different plasticity-related genes are up- and downregulated by sleep after the initial IEG response, pointing to complex changes in gene expression related to dendritic reshaping [106].

To which extent is post-learning sleep determinant of experience-dependent synaptic upscaling? Light on this question was shed by Ted Abel's laboratory. The researchers began by determining the cognitive effects of sleep deprivation for $5 \mathrm{~h}$ after training for contextual and cued fear conditioning, the former dependent and the latter independent of the hippocampus. Cued fear conditioning was insensitive to both sleep deprivation schedules. Contextual fear conditioning, however, was dependent on post-learning sleep for consolidation. Sleep deprivation from $0-5 \mathrm{~h}$ after training decreased performance on contextual fear conditioning, while sleep deprivation from $5-10 \mathrm{~h}$ after training did not impair learning [43]. The same research team went on to show that the detrimental effects of sleep deprivation on contextual fear conditioning were caused by a disruption of synaptic plasticity that depends on the cAMP/PKA pathway [134]. The experiments involved a 5-h period of sleep deprivation followed by in vitro electrophysiological recordings and stimulation of hippocampal slices of animals pre-exposed (or not) to contextual fear conditioning. Various forms of
NMDA receptor-dependent LTP involving different molecular mechanisms were investigated. Two of these LTP forms, both dependent on cAMP, PKA, transcription, and translation, were impaired in hippocampal slices from sleep-deprived mice. Sleep did not affect two other forms of LTP that are independent of cAMP/ PKA signaling. Since one of these is dependent on translation, the authors concluded that brief sleep deprivation must impair synaptic plasticity at a biochemical level prior to translation. Pharmacological and biochemical assays showed that sleep deprivation limits the ability of hippocampal neurons to undergo adenylate cyclase activation. In particular, sleep deprivation decreases CREB phosphorylation that requires cAMP signaling and is required for zif-268 transcriptional regulation. The researchers focused on a good candidate for being responsible for the effects: cyclic nucleotide phosphodiesterases (PDE), the enzymes in charge of cAMP degradation [55]. Further experiments showed that PDE inhibitors were able to rescue cAMP-dependent plasticity and cAMP levels in slices from sleep-deprived mice. PDE-specific cAMP breakdown was increased in sleep-deprived mice, and in vivo PDE inhibition rescued the deficit in context-specific memory induced by sleep deprivation [43, 134].

Until these groundbreaking experiments, the cognitive impairment caused by sleep deprivation could only be rescued by sleep itself. The results demonstrate that the synaptic plasticity and memory deficits elicited by sleep deprivation can be rescued with a PDE inhibitor. In sum, the results demonstrate that sustained waking disrupts hippocampal function via a reduction in cAMP signaling caused by an increase in the levels of PDE. By the same token, sleep decreases PDE levels and therefore promotes an increase in cAMP, thus leading to synaptic potentiation.

\section{Sleep-dependent synaptic embossing accounts well for the available data}

Can synaptic downscaling linked to passive quiescence really explain the cognitive role of sleep, or is there a theoretical need for active upscaling mechanisms? The current mainstream theory sustains that sleep benefits learning by promoting global synaptic downscaling, able in principle to restore homeostatic balance and enable further waking potentiation [126]. This theory embodies a revival of the passive view of sleep function, which was dominant before the discovery of REM. It focuses exclusively on SWS and finds no place for experiencedependent changes during sleep. In contrast, the contender theory considers sleep as a combination of passive and 
active mechanisms, distinguishes the contributions of SWS and REM, and stresses the need to compare sleep with and without prior learning [23, 102]. This synaptic embossing theory proposes that sleep facilitates learning because of the cooperative interaction of its two major states: While SWS reverberates memories in the absence of sensory interference, REM triggers plasticity-related metabolic cascades in selected neuronal networks previously activated during waking and engaged in mnemonic reverberation during SWS [23, 102]. It follows from this view that sleep influences synaptic plasticity bidirectionally, simultaneously promoting synaptic down and upscaling in separate neuronal networks. Such a process would lead to experience-dependent differential plasticity (or simply "synaptic embossing"), with nonHebbian generalized synaptic downscaling in the background and Hebbian upscaling of selected synapses in the foreground.

More experimentation is necessary to convincingly refute either theory. At the 2009 meeting of the Society for Neuroscience, our group presented novel molecular, electrophysiological, and computational results that corroborate the synaptic embossing theory (manuscripts in preparation). We reported an increase in the phosphorylation of CaMKII during REM that follows novel object exploration [91]. We also showed that post-novelty increases in sleep firing rates affect the same neurons that were activated by novel simulation during precedent waking experience [28]. Finally, a computer simulation of synaptic weight changes across the sleep-wake cycle using real neuronal data as inputs revealed that REM leads to an increase in synaptic weights in comparison with SWS, due to the higher firing rates of REM [3]. In this computer simulation, the addition during REM of experience-dependent gene expression able to promote long-term synaptic upscaling leads to a marked redistribution of synaptic weights over time. This effect is stochastic in the sense that it depends on the random fluctuations of the synaptic weights at the SWS/REM boundary. The results seem to implement mechanistically the concept of "stochastic resonance" [38, 73] during REM, which has been postulated to form new mnemonic associations and to promote consolidation at synapses activated during prior SWS [24].

Many intriguing questions about the mechanisms of sleep-dependent plasticity remain completely or partially unanswered. What is the exact role played by dopamine? Is acetylcholine, highly abundant during REM, also involved? What is the role of cortisol? What kind of neuronal and local field potential activity is necessary to trigger or deactivate the cAMP/PKA pathway during sleep? How are synapses tagged by waking experience for subsequent sleep plasticity? What is the contribution of these mechanisms for the displacement of memory traces across hippocampocortical circuits?
Above and beyond the many open questions and the present divergence regarding sleep-dependent plasticity, it is clear that synaptic upscaling and downscaling are not mutually exclusive. Experience-dependent synaptic upscaling is compatible with global synaptic downscaling, as long as the two processes occur in separate neuronal networks [102]. Synaptic downscaling during SWS is most surely crucial for learning, but if it were to occur with equal strength in activated and non-activated networks, it would lead to generalized forgetting, not specific learning. I have previously proposed that the combination of synaptic upscaling in selected networks and synaptic downscaling in non-selected networks should greatly increase the signalto-noise ratio of sleep-dependent memory consolidation [94]. Such differential upscaling of synaptic weights seems apt to carve high-relief memory traces over a background of downscaled synapses, leading to the concept of synaptic embossing. A comparison of stimulated and non-stimulated cortical areas related to different sensory modalities indicates that this is indeed the case [104]. The Drosophila data recently published by Donlea and collaborators show that sleep not only restores the capacity for learning but also enhances the duration of memories, a positive effect that can only be explained with some kind of absolute or relative synaptic upscaling [26].

One necessary consequence of the embossing theory is that the net change in synaptic strength during sleep is related to the encoding strength of the preceding waking experience, i.e., by how much synaptic change resulted from the encoding conditions. Context fear conditioning, for instance, is a single trial training paradigm that involves painful, very salient stimuli. As a consequence, context fear conditioning probably determines a great deal of synaptic upscaling during encoding, which is likely to cause major synaptic upscaling during subsequent sleep [43, 134]. It follows from this line of reasoning that different training paradigms will be associated with distinct net balances of synaptic up- and downscaling during subsequent sleep.

The coming years should witness the sleep and memory fields finally agree on the issue of plasticity. Most likely, it will be a convergence on the middle road. Synaptic embossing is the most parsimonious explanation for sleep's striking ability to consolidate relevant memories while at the same time leading to the forgetting of irrelevant ones, so as to recover the capacity for new learning. The best explanation for the cognitive role of sleep is neither synaptic downscaling nor upscaling exclusively but rather the concerted action of both.

Acknowledgments I thank Jan Born, Rodrigo Romcy-Pereira, and an anonymous reviewer for critical reviews of the manuscript, which helped to balance and increase the depth of the material covered. 
Open Access This article is distributed under the terms of the Creative Commons Attribution Noncommercial License which permits any noncommercial use, distribution, and reproduction in any medium, provided the original author(s) and source are credited.

\section{References}

1. Allen PB, Ouimet CC, Greengard P (1997) Spinophilin, a novel protein phosphatase 1 binding protein localized to dendritic spines. Proc Natl Acad Sci USA 94(18):9956-9961

2. Aton SJ, Seibt J, Dumoulin M, Jha SK, Steinmetz N, Coleman T, Naidoo N, Frank MG (2009) Mechanisms of sleep-dependent consolidation of cortical plasticity. Neuron 61(3):454-466

3. Blanco W, Guerreiro AMG, Nicolelis MAL, Ribeiro SA (2009) Boltzmann machine model of memory maintenance and restructuring during sleep: An annealing process. In: Meeting of the Society for Neuroscience, Chicago. Society for Neuroscience, p 486.484

4. Bliss TV, Collingridge GL (1993) A synaptic model of memory: long-term potentiation in the hippocampus. Nature 361(6407):3139

5. Bozon B, Kelly A, Josselyn SA, Silva AJ, Davis S, Laroche S (2003) MAPK, CREB and zif268 are all required for the consolidation of recognition memory. Philos Trans R Soc Lond B Biol Sci 358(1432):805-814

6. Bushey D, Huber R, Tononi G, Cirelli C (2007) Drosophila Hyperkinetic mutants have reduced sleep and impaired memory. J Neurosci 27(20):5384-5393

7. Bushey D, Tononi G, Cirelli C (2011) Sleep and synaptic homeostasis: structural evidence in Drosophila. Science 332 (6037):1576-1581

8. Christy B, Nathans D (1989) DNA binding site of the growth factor-inducible protein Zif268. Proc Natl Acad Sci USA 86 (22):8737-8741

9. Cirelli C (2005) A molecular window on sleep: changes in gene expression between sleep and wakefulness. Neuroscientist 11 (1):63-74

10. Cirelli C (2006) Sleep disruption, oxidative stress, and aging: new insights from fruit flies. Proc Natl Acad Sci USA 103 (38):13901-13902

11. Cirelli C, Bushey D, Hill S, Huber R, Kreber R, Ganetzky B, Tononi G (2005) Reduced sleep in Drosophila Shaker mutants. Nature 434(7037):1087-1092

12. Cirelli C, Faraguna U, Tononi G (2006) Changes in brain gene expression after long-term sleep deprivation. J Neurochem 98 (5):1632-1645

13. Cirelli C, Gutierrez CM, Tononi G (2004) Extensive and divergent effects of sleep and wakefulness on brain gene expression. Neuron 41(1):35-43

14. Cirelli C, LaVaute TM, Tononi G (2005) Sleep and wakefulness modulate gene expression in Drosophila. J Neurochem 94 (5):1411-1419

15. Cirelli C, Tononi G (1998) Differences in gene expression between sleep and waking as revealed by mRNA differential display. Brain Res Mol Brain Res 56(1-2):293-305

16. Cirelli C, Tononi G (1999) Differences in brain gene expression between sleep and waking as revealed by mRNA differential display and cDNA microarray technology. J Sleep Res 8(Suppl 1):44-52

17. Cirelli C, Tononi G (1999) Differences in gene expression during sleep and wakefulness. Ann Med 31(2):117-124

18. Cirelli C, Tononi G (2000) Differential expression of plasticityrelated genes in waking and sleep and their regulation by the noradrenergic system. J Neurosci 20(24):9187-9194
19. Cirelli C, Tononi G (2000) Gene expression in the brain across the sleep-waking cycle. Brain Res 885(2):303-321

20. Clemens Z, Molle M, Eross L, Jakus R, Rasonyi G, Halasz P, Born J (2011) Fine-tuned coupling between human parahippocampal ripples and sleep spindles. Eur J Neurosci 33(3):511-520

21. Comery TA, Shah R, Greenough WT (1995) Differential rearing alters spine density on medium-sized spiny neurons in the rat corpus striatum: evidence for association of morphological plasticity with early response gene expression. Neurobiol Learn Memory 63(3):217-219

22. Dave AS, Margoliash D (2000) Song replay during sleep and computational rules for sensorimotor vocal learning. Science 290 (5492):812-816

23. Diekelmann S, Born J (2010) The memory function of sleep. Nat Rev Neurosci 11(2):114-126

24. Diekelmann S, Born J (2011) Commentary on A. Hobson's "Dream Consciousness". Unpublished, Vienna Circle

25. Diekelmann S, Buchel C, Born J, Rasch B (2011) Labile or stable: opposing consequences for memory when reactivated during waking and sleep. Nat Neurosci 14:381-386

26. Donlea JM, Thimgan MS, Suzuki Y, Gottschalk L, Shaw PJ (2011) Inducing sleep by remote control facilitates memory consolidation in Drosophila. Science 332(6037):1571-1576

27. Eschenko O, Molle M, Born J, Sara SJ (2006) Elevated sleep spindle density after learning or after retrieval in rats. J Neurosci 26(50):12914-12920

28. Faber J, Nicolelis MAL, Ribeiro S (2009) Entropy methods to measure neuronal reverberation during post-learning sleep. In: Society of Neuroscience Meeting, Chicago. Society for Neuroscience, $\mathrm{p} 894.897$

29. Fishbein W, McGaugh JL, Swarz JR (1971) Retrograde amnesia: electroconvulsive shock effects after termination of rapid eye movement sleep deprivation. Science 172(978):80-82

30. Fishbein W, Schaumburg H, Weitzman ED (1966) Rapid eye movements during sleep in dark-reared kittens. J Nerv Ment Dis 143(3):281-283

31. Fogel SM, Smith CT (2006) Learning-dependent changes in sleep spindles and Stage 2 sleep. J Sleep Res 15(3):250 255

32. Fogel SM, Smith CT (2011) The function of the sleep spindle: a physiological index of intelligence and a mechanism for sleepdependent memory consolidation. Neurosci Biobehav Rev 35:1154-1165

33. Frank MG, Issa NP, Stryker MP (2001) Sleep enhances plasticity in the developing visual cortex. Neuron 30(1):275-287

34. Frankland PW, O'Brien C, Ohno M, Kirkwood A, Silva AJ (2001) Alpha-CaMKII-dependent plasticity in the cortex is required for permanent memory. Nature 411(6835):309-313

35. Gais S, Albouy G, Boly M, Dang-Vu TT, Darsaud A, Desseilles M, Rauchs G, Schabus M, Sterpenich V, Vandewalle G, Maquet P, Peigneux P (2007) Sleep transforms the cerebral trace of declarative memories. Proc Natl Acad Sci USA 104(47):18778-18783

36. Gais S, Born J (2004) Declarative memory consolidation: mechanisms acting during human sleep. Learn Mem 11 (6):679-685

37. Gais S, Molle M, Helms K, Born J (2002) Learning-dependent increases in sleep spindle density. J Neurosci 22(15):6830-6834

38. Gammaitoni L, Hänggi P, Jung P, Marchesoni F (1998) Stochastic resonance. Rev Mod Phys 70:223-287

39. Ganguly-Fitzgerald I, Donlea J, Shaw PJ (2006) Waking experience affects sleep need in Drosophila. Science 313 (5794):1775-1781

40. Gervasoni D, Lin SC, Ribeiro S, Soares ES, Pantoja P, Nicolelis M (2004) Global forebrain dynamics predict rat behavioral states and their transitions. J Neurosci 24(49):11137-11147 
41. Giuditta A (ed) (1985) A sequential hypothesis for the function of sleep. Sleep in '84. Fisher-Verlag, Stuttgart

42. Gold PE (2008) Protein synthesis inhibition and memory: formation vs. amnesia. Neurobiol Learn Mem 89:201-211

43. Graves LA, Heller EA, Pack AI, Abel T (2003) Sleep deprivation selectively impairs memory consolidation for contextual fear conditioning. Learn Mem 10:168-176

44. Green EJ, Greenough WT (1986) Altered synaptic transmission in dentate gyrus of rats reared in complex environments: evidence from hippocampal slices maintained in vitro. J Neurophysiol 55:739-750

45. Greenough WT, Juraska JM, Volkmar FR (1979) Maze training effects on dendritic branching in occipital cortex of adult rats. Behav Neural Biol 26:287-297

46. Gutwein BM, Shiromani PJ, Fishbein W (1980) Paradoxical sleep and memory: long-term disruptive effects of Anisomycin. Pharmacol Biochem Behav 12(3):377-384

47. Guzowski JF, Lyford GL, Stevenson GD, Houston FP, McGaugh JL, Worley PF, Barnes CA (2000) Inhibition of activitydependent arc protein expression in the rat hippocampus impairs the maintenance of long-term potentiation and the consolidation of long-term memory. J Neurosci 20(11):3993-4001

48. Hanlon EC, Faraguna U, Vyazovskiy VV, Tononi G, Cirelli C (2009) Effects of skilled training on sleep slow wave activity and cortical gene expression in the rat. Sleep 32(6):719-729

49. Hebb DO (1949) The organization of behavior: a neuropsychological theory. Wiley, New York

50. Hennevin E, Hars B, Maho C (1995) Memory processing in paradoxical sleep. Sleep Research Society Bulletin 1:44-50

51. Hennevin E, Leconte P (1977) [Study of the relations between paradoxical sleep and learning processes (author's transl)]. [French]. Physiol Behav 18(2):307-319

52. Hilfiker S, Pieribone VA, Czernik AJ, Kao HT, Augustine GJ, Greengard P (1999) Synapsins as regulators of neurotransmitter release. Philos Trans R Soc Lond B Biol Sci 354(1381):269-279

53. Hirase H, Leinekugel X, Czurko A, Csicsvari J, Buzsaki G (2001) Firing rates of hippocampal neurons are preserved during subsequent sleep episodes and modified by novel awake experience. Proc Natl Acad Sci USA 98(16):9386-9390

54. Hoffman KL, McNaughton B (2002) Coordinated reactivation of distributed memory traces in primate neocortex. Science 297 (5589):2070-2073

55. Houslay MD, Adams DR (2003) PDE4 cAMP phosphodiesterases: modular enzymes that orchestrate signalling cross-talk, desensitization and compartmentalization. Biochem J 370:1-18

56. Huber R, Hill SL, Holladay C, Biesiadecki M, Tononi G, Cirelli C (2004) Sleep homeostasis in Drosophila melanogaster. Sleep 27(4):628-639

57. Jenkins JB, Dallenbach KM (1924) Oblivescence during sleep and waking. Am J of Psychology 35:605-612

58. Laureys S, Peigneux P, Perrin F, Maquet P (2002) Sleep and motor skill learning. Neuron 35(1):5-7

59. Laureys S, Peigneux P, Phillips C, Fuchs S, Degueldre C, Aerts J, Del Fiore G, Petiau C, Luxen A, van der Linden M, Cleeremans A, Smith C, Maquet P (2001) Experiencedependent changes in cerebral functional connectivity during human rapid eye movement sleep. Neuroscience 105(3):521-525

60. Leconte P, Bloch V (1970) Déficit de la rétention d'un conditionnement après privation de sommeil paradoxal chez le rat. Comptes Rendus de l'Académie des Sciences (Paris) 271D:226-229

61. Lee AK, Wilson MA (2002) Memory of sequential experience in the hippocampus during slow wave sleep. Neuron 36(6):11831194

62. Lewis PA, Couch TJ, Walker MP (2011) Keeping time in your sleep: overnight consolidation of temporal rhythm. Neuropsychologia 49(1):115-123
63. Lisman J, Schulman H, Cline H (2002) The molecular basis of CaMKII function in synaptic and behavioural memory. Nat Rev Neurosci 3(3):175-190

64. Liu ZW, Faraguna U, Cirelli C, Tononi G, Gao XB (2010) Direct evidence for wake-related increases and sleep-related decreases in synaptic strength in rodent cortex. J Neurosci 30(25):86718675

65. Lopes da Silva F (1991) Neural mechanisms underlying brain waves: from neural membranes to networks. Electroencephalogr Clin Neurophysiol 79:81-93

66. Lopez J, Roffwarg HP, Dreher A, Bissette G, Karolewicz B, Shaffery JP (2008) Rapid eye movement sleep deprivation decreases longterm potentiation stability and affects some glutamatergic signaling proteins during hippocampal development. Neuroscience 153 (1):44-53

67. Louie K, Wilson MA (2001) Temporally structured replay of awake hippocampal ensemble activity during rapid eye movement sleep. Neuron 29(1):145-156

68. Lyford GL, Yamagata K, Kaufmann WE, Barnes CA, Sanders LK, Copeland NG, Gilbert DJ, Jenkins NA, Lanahan AA, Worley PF (1995) Arc, a growth factor and activity-regulated gene, encodes a novel cytoskeleton-associated protein that is enriched in neuronal dendrites. Neuron 145(2):433-434

69. Malenka RC, Nicoll RA (1993) NMDA-receptor-dependent synaptic plasticity - multiple forms and mechanisms. TINS 16 (12):521-527

70. Maquet P (2001) The role of sleep in learning and memory. Science 294(5544):1048-1052

71. Maquet P, Laureys S, Peigneux P, Fuchs S, Petiau C, Phillips C, Aerts J, Del Fiore G, Degueldre C, Meulemans T, Luxen A, Franck G, Van Der Linden M, Smith C, Cleeremans A (2000) Experience-dependent changes in cerebral activation during human REM sleep. Nat Neurosci 3(8):831-836

72. Matsuzaki M, Honkura N, Ellis-Davies GC, Kasai H (2004) Structural basis of long-term potentiation in single dendritic spines. Nature 429(6993):761-766

73. McDonnell MD, Abbott D (2009) What is stochastic resonance? Definitions, misconceptions, debates, and its relevance to biology. PLoS Comput Biol 5:e1000348

74. McGaugh JL (2000) Memory - a century of consolidation. Science 287(5451):248-251

75. Mednick SC, Drummond SP, Boynton GM, Awh E, Serences J (2008) Sleep-dependent learning and practice-dependent deterioration in an orientation discrimination task. Behav Neurosci 122 (2):267-272

76. Mednick SC, Nakayama K, Cantero JL, Atienza M, Levin AA, Pathak N, Stickgold R (2002) The restorative effect of naps on perceptual deterioration. Nat Neurosci 5(7):677-681

77. Mednick SC, Nakayama K, Stickgold R (2003) Sleep-dependent learning: a nap is as good as a night. Nat Neurosci 6:697-698

78. Milbrandt J (1987) A nerve growth factor-induced gene encodes a possible transcriptional regulatory factor. Science 238 (4828):797-799

79. Molle M, Eschenko O, Gais S, Sara SJ, Born J (2009) The influence of learning on sleep slow oscillations and associated spindles and ripples in humans and rats. Eur J Neurosci 29(5):1071-1081

80. Molle M, Marshall L, Gais S, Born J (2004) Learning increases human electroencephalographic coherence during subsequent slow sleep oscillations. Proc Natl Acad Sci USA 101(38):13963-13968

81. Molle M, Yeshenko O, Marshall L, Sara SJ, Born J (2006) Hippocampal sharp wave-ripples linked to slow oscillations in rat slow-wave sleep. J Neurophysiol 96(1):62-70

82. Nadasdy Z, Hirase H, Czurko A, Csicsvari J, Buzsaki G (1999) Replay and time compression of recurring spike sequences in the hippocampus. J Neurosci 19(21):9497-9507 
83. Nishida M, Walker MP (2007) Daytime naps, motor memory consolidation and regionally specific sleep spindles. PLoS One 2 (4): $\mathrm{e} 341$

84. Nunez PL (1981) Electric fields of the brain: the neurophysics of EEG. Oxford University Press, New York

85. O'Hara BF, Young KA, Watson FL, Heller HC, Kilduff TS (1993) Immediate early gene expression in brain during sleep deprivation: preliminary observations. Sleep 16(1):1-7

86. Olcese U, Esser SK, Tononi G (2010) Sleep and synaptic renormalization: a computational study. J Neurophysiol 104 (6):3476-3493

87. Orban P, Rauchs G, Balteau E, Degueldre C, Luxen A, Maquet P, Peigneux P (2006) Sleep after spatial learning promotes covert reorganization of brain activity. Proc Natl Acad Sci USA 103 (18):7124-7129

88. Pavlides C, Winson J (1989) Influences of hippocampal place cell firing in the awake state on the activity of these cells during subsequent sleep episodes. J Neurosci 9(8):2907-2918

89. Payne JD, Nadel L (2004) Sleep, dreams, and memory consolidation: the role of the stress hormone cortisol. Learn Mem 11(6):671-678

90. Peigneux P, Laureys S, Fuchs S, Destrebecqz A, Collette F, Delbeuck X, Phillips C, Aerts J, Del Fiore G, Degueldre C, Luxen A, Cleeremans A, Maquet P (2003) Learned material content and acquisition level modulate cerebral reactivation during posttraining rapid-eye-movements sleep. NeuroImage 20 (1):125-134

91. Pereira CM, Cota VR, Santos S, Dias G, Souza AC, Nicolelis MAL, Ribeiro S (2009) Experience-dependent reactivation of the calcium signal transduction pathway in the rat hippocampus during sleep. In: Meeting of the Society for Neuroscience, Chicago. Society for Neuroscience, p 585.582

92. Petersohn D, Schoch S, Brinkmann DR, Thiel G (1995) The human synapsin II gene promoter. Possible role for the transcription factor zif268/egr-1, polyoma enhancer activator 3, and AP2. J Biol Chem 270(41):24361-24369

93. Poe GR, Walsh CM, Bjorness TE (2010) Cognitive neuroscience of sleep. In: Kerkhof GA, Van Dongen HPA (eds) Human sleep and cognition: progress in brain research, vol 185. Elsevier, Oxford, pp 1-19

94. Pompeiano M, Cirelli C, Arrighi P, Tononi G (1995) c-Fos expression during wakefulness and sleep. Neurophysiol Clin 25 (6):329-341

95. Pompeiano M, Cirelli C, Ronca-Testoni S, Tononi G (1997) NGFI-A expression in the rat brain after sleep deprivation. Brain Res Mol Brain Res 46(1-2):143-153

96. Pompeiano M, Cirelli C, Tononi G (1992) Effects of sleep deprivation on fos-like immunoreactivity in the rat brain. Arch Ital Biol 130(4):325-335

97. Pompeiano M, Cirelli C, Tononi G (1994) Immediate-early genes in spontaneous wakefulness and sleep: expression of c-fos and NGIF-A mRNA and protein. J Sleep Res 3:80-96

98. Qin YL, McNaughton BL, Skaggs WE, Barnes CA (1997) Memory reprocessing in corticocortical and hippocampocortical neuronal ensembles. Philos Trans R Soc Lond B Biol Sci 352 (1360):1525-1533

99. Ribeiro S, Gervasoni D, Soares ES, Zhou Y, Lin SC, Pantoja J, Lavine M, Nicolelis MA (2004) Long-lasting novelty-induced neuronal reverberation during slow-wave sleep in multiple forebrain areas. PLoS Biol 2(1):E24

100. Ribeiro S, Goyal V, Mello CV, Pavlides C (1999) Brain gene expression during REM sleep depends on prior waking experience. Learn Mem 6(5):500-508

101. Ribeiro S, Mello CV, Velho T, Gardner TJ, Jarvis ED, Pavlides C (2002) Induction of hippocampal long-term potentiation during waking leads to increased extrahippocampal zif-268 expression during ensuing rapid-eye- movement sleep. J Neurosci 22 (24):10914-10923

102. Ribeiro S, Nicolelis MAL (2004) Reverberation, storage and postsynaptic propagation of memories during sleep. Learn Mem 11(6):686-696

103. Ribeiro S, Pereira CM, Faber J, Blanco W, Nicolelis MAL (2009) Downscale or emboss synapses during sleep? Front Neurosci 3:420-421

104. Ribeiro S, Shi X, Engelhard M, Zhou Y, Zhang H, Gervasoni D, Lin SC, Wada K, Lemos NAM, Nicolelis MAL (2007) Novel experience induces persistent sleepdependent plasticity in the cortex but not in the hippocampus. Front Neurosci 1(1):43-55

105. Rieth CA, Cai DJ, McDevitt EA, Mednick SC (2010) The role of sleep and practice in implicit and explicit motor learning. Behav Brain Res 214(2):470-474

106. Romcy-Pereira RN, Erraji-Benchekroun L, Smyrniotopoulos P, Ogawa S, Mello CV, Sibille E, Pavlides C (2009) Sleepdependent gene expression in the hippocampus and prefrontal cortex following long-term potentiation. Physiol Behav 98(12):44-52

107. Rosanova M, Ulrich D (2005) Pattern-specific associative longterm potentiation induced by a sleep spindle-related spike train. $\mathrm{J}$ Neurosci 25(41):9398-9405

108. Schabus M, Gruber G, Parapatics S, Sauter C, Klosch G, Anderer P, Klimesch W, Saletu B, Zeitlhofer J (2004) Sleep spindles and their significance for declarative memory consolidation. Sleep 27(8):1479-1485

109. Schabus M, Hodlmoser K, Gruber G, Sauter C, Anderer P, Klosch G, Parapatics S, Saletu B, Klimesch W, Zeitlhofer J (2006) Sleep spindle-related activity in the human EEG and its relation to general cognitive and learning abilities. Eur J Neurosci 23(7):1738-1746

110. Schmitt JM, Guire ES, Saneyoshi T, Soderling TR (2005) Calmodulin-dependent kinase kinase/calmodulin kinase I activity gates extracellular-regulated kinase-dependent long-term potentiation. J Neurosci 25:1281-1290

111. Seugnet L, Suzuki Y, Donlea JM, Gottschalk L, Shaw PJ (2011) Sleep deprivation during early-adult development results in longlasting learning deficits in adult Drosophila. Sleep 34(2):137146

112. Shaffery JP, Lopez J, Bissette G, Roffwarg HP (2006) Rapid eye movement sleep deprivation revives a form of developmentally regulated synaptic plasticity in the visual cortex of post-critical period rats. Neurosci Lett 391(3):96-101

113. Shaffery JP, Oksenberg A, Marks GA, Speciale SG, Mihailoff G, Roffwarg HP (1998) REM sleep deprivation in monocularly occluded kittens reduces the size of cells in LGN monocular segment. Sleep 21(8):837-845

114. Shaffery JP, Roffwarg HP (2003) Rapid eye-movement sleep deprivation does not 'rescue' developmentally regulated longterm potentiation in visual cortex of mature rats. Neurosci Lett 342(3):196-200

115. Shaffery JP, Sinton CM, Bissette G, Roffwarg HP, Marks GA (2002) Rapid eye movement sleep deprivation modifies expression of long-term potentiation in visual cortex of immature rats. Neuroscience 110(3):431-443

116. Shaw PJ, Cirelli C, Greenspan RJ, Tononi G (2000) Correlates of sleep and waking in Drosophila melanogaster. Science 287 (5459):1834-1837

117. Skaggs WE, McNaughton BL (1996) Replay of neuronal firing sequences in rat hippocampus during sleep following spatial experience. Science 271(5257):1870-1873

118. Smith C, Kitahama K, Valatx JL, Jouvet M (1974) Increased paradoxical sleep in mice during acquisition of a shock avoidance task. Brain Res 77(2):221-230 
119. Smith C, MacNeill C (1993) A paradoxical sleep-dependent window for memory 53-56-H after the end of avoidance training. Psychobiology 21(2):109-112

120. Steward O, Wallace CS, Lyford GL, Worley PF (1998) Synaptic activation causes the mRNA for the IEG Arc to localize selectively near activated postsynaptic sites on dendrites. Neuron 21(4):741-751

121. Stickgold R (1998) Sleep: off-line memory reprocessing. Trends Cogn Sci 2:484-492

122. Tamaki M, Matsuoka T, Nittono H, Hori T (2008) Fast sleep spindle $(13-15 \mathrm{hz})$ activity correlates with sleep-dependent improvement in visuomotor performance. Sleep 31(2):204-211

123. Tamaki M, Matsuoka T, Nittono H, Hori T (2009) Activation of fast sleep spindles at the premotor cortex and parietal areas contributes to motor learning: a study using sLORETA. Clin Neurophysiol 120(5):878-886

124. Tamminen J, Payne JD, Stickgold R, Wamsley EJ, Gaskell MG (2010) Sleep spindle activity is associated with the integration of new memories and existing knowledge. J Neurosci 30 (43): $14356-14360$

125. Thiel G, Schoch S, Petersohn D (1994) Regulation of synapsin I gene expression by the zinc finger transcription factor zif268/ egr-1. J Biol Chem 269(21):15294-15301

126. Tononi G, Cirelli C (2003) Sleep and synaptic homeostasis: a hypothesis. Brain Res Bull 62(2):143-150

127. Tononi G, Cirelli C (2006) Sleep function and synaptic homeostasis. Sleep Med Rev 10(1):49-62

128. Tononi G, Cirelli C, Pompeiano M (1995) Changes in gene expression during the sleep-waking cycle: a new view of activating systems. Arch Ital Biol 134(1):21-37

129. Tononi G, Pompeiano M, Cirelli C (1994) The locus coeruleus and immediate-early genes in spontaneous and forced wakefulness. Brain Res Bull 35(5-6):589-596

130. Turrigiano GG (1999) Homeostatic plasticity in neuronal networks: the more things change, the more they stay the same. Trends Neurosci 22(5):221-227

131. Turrigiano GG, Leslie KR, Desai NS, Rutherford LC, Nelson SB (1998) Activity-dependent scaling of quantal amplitude in neocortical neurons. Nature 391(6670):892-896

132. Turrigiano GG, Nelson SB (2000) Hebb and homeostasis in neuronal plasticity. Curr Opin Neurobiol 10(3):358-364

133. Ulloor J, Datta S (2005) Spatio-temporal activation of cyclic AMP response element-binding protein, activity-regulated cytoskeletal-associated protein and brain-derived nerve growth factor: a mechanism for pontine-wave generator activationdependent two-way active-avoidance memory processing in the rat. J Neurochem 95(2):418-428

134. Vecsey CG, Baillie GS, Jaganath D, Havekes R, Daniels A, Wimmer M, Huang T, Brown KM, Li XY, Descalzi G, Kim SS, Chen T, Shang YZ, Zhuo M, Houslay MD, Abel T (2009) Sleep deprivation impairs cAMP signalling in the hippocampus. Nature 461(7267):1122-1125

135. Vyazovskiy VV, Cirelli C, Pfister-Genskow M, Faraguna U, Tononi G (2008) Molecular and electrophysiological evidence for net synaptic potentiation in wake and depression in sleep. Nat Neurosci 11(2):200-208

136. Wagner U, Gais S, Haider H, Verleger R, Born J (2004) Sleep inspires insight. Nature 427(6972):352-355

137. Walker MP, Brakefield T, Hobson JA, Stickgold R (2003) Dissociable stages of human memory consolidation and reconsolidation. Nature 425(6958):616-620

138. Walker MP, Brakefield T, Morgan A, Hobson JA, Stickgold R (2002) Practice with sleep makes perfect: sleep-dependent motor skill learning. Neuron 35(1):205-211

139. Walker MP, Brakefield T, Seidman J, Morgan A, Hobson JA, Stickgold R (2003) Sleep and the time course of motor skill learning. Learn Mem 10(4):275-284

140. Walker MP, Stickgold R (2004) Sleep-dependent learning and memory consolidation. Neuron 44(1):121-133

141. Wallace CS, Withers GS, Weiler IJ, George JM, Clayton DF, Greenough WT (1995) Correspondence between sites of NGFIA induction and sites of morphological plasticity following exposure to environmental complexity. Brain Res Mol Brain Res 32(2):211-220

142. Waltereit R, Dammermann B, Wulff P, Scafidi J, Staubli U, Kauselmann G, Bundman M, Kuhl D (2001) Arg3.1/Arc mRNA induction by $\mathrm{Ca}^{2+}$ and cAMP requires protein kinase $\mathrm{A}$ and mitogen-activated protein kinase/extracellular regulated kinase activation. J Neurosci 21(15):5484-5493

143. Wamsley EJ, Tucker M, Payne JD, Benavides JA, Stickgold R (2010) Dreaming of a learning task is associated with enhanced sleep-dependent memory consolidation. Curr Biol 20(9):850-855

144. Wamsley EJ, Tucker MA, Payne JD, Stickgold R (2010) A brief nap is beneficial for human route-learning: the role of navigation experience and EEG spectral power. Learn Mem 17(7):332-336

145. Weiler IJ, Hawrylak N, Greenough WT (1995) Morphogenesis in memory formation: synaptic and cellular mechanisms. Behav Brain Res 66(1-2):1-6

146. Wierzynski CM, Lubenov EV, Gu M, Siapas AG (2009) Statedependent spike-timing relationships between hippocampal and prefrontal circuits during sleep. Neuron 61(4):587-596

147. Wilhelm I, Diekelmann S, Molzow I, Ayoub A, Molle M, Born J (2011) Sleep selectively enhances memory expected to be of future relevance. J Neurosci 31(5):1563-1569

148. Wilson MA, McNaughton BL (1994) Reactivation of hippocampal ensemble memories during sleep. Science 265(5172):676679

149. Wisden W, Errington ML, Williams S, Dunnett SB, Waters C, Hitchcock D, Evan G, Bliss TV, Hunt SP (1990) Differential expression of immediate early genes in the hippocampus and spinal cord. Neuron 4(4):603-614

150. Witt K, Margraf N, Bieber C, Born J, Deuschl G (2010) Sleep consolidates the effector-independent representation of a motor skill. Neuroscience 171(1):227-234

151. Yoo SS, Hu PT, Gujar N, Jolesz FA, Walker MP (2007) A deficit in the ability to form new human memories without sleep. Nat Neurosci 10(3):385-392 